\title{
Exacerbation of Migraines Following Robotic Surgery for Endometrial Carcinoma
}

\author{
John P Geisler ${ }^{1} \&$ Kelly J Manahan ${ }^{1}$ \\ ${ }^{1}$ Cancer Treatment Centers of America, Newnan, Georgia, USA \\ Correspondence: John P Geisler, MD; Cancer Treatment Centers of America, USA. Tel: 1-770-400-6000. E-mail: \\ Geisler.jp@gmail.com
}

Received: September 6, 2015

Accepted: September 27, 2015 Online Published: October 22, 2015

doi:10.5539/cco.v4n2p53

URL: http://dx.doi.org/10.5539/cco.v4n2p53

\begin{abstract}
Objective: Robotic hysterectomies are becoming increasingly common in the United States. Although benefits exist, risks are also present. The purpose of this study was to see what percentage of women with migraine headaches had a post-operative exacerbation.

Study design: Records were examined for the diagnosis of migraine headaches as well as post-operative diagnosis of a headache. Records were also examined for age, estimated blood loss, total skin to skin operative time and body mass index.

Results: Surgeries and records for 100 women were examined. Only $6 \%$ of women complained of post-operative headaches. However, $45 \%$ of women with history of migraines complained of post-operative headaches $(\mathrm{p}<0.001)$. Age was the only significant factor with women having post-operative headaches being significantly younger $(\mathrm{p}=0.009)$.
\end{abstract}

Conclusion: Post-operative headaches were more common in women with a pre-operative history of migraine headaches than in those without a history. Patients with a history of migraines should be warned of this risk.

Keywords: robotics, migraines, Trendelenburg, endometrial cancer

\section{Introduction}

Since its initial development in the early 1970's, robotic-assisted laparoscopic surgery has become an increasingly popular procedure. The use of robotics in gynecologic surgery has been demonstrated in a wide range of cases, with application for both benign and malignant conditions. One such disease that can be staged and/or treated with robotic hysterectomy is endometrial carcinoma. This is the most common type of gynecologic malignancy in developed countries, and the second most common worldwide following cervical cancer (Creutzberg, van Putten, \& Kope, 2000; Benedet, Bender, Jones, Ngan, \& Pecorelli, 2000). It was projected that in 2013, there will be approximately 54,870 new cases of cancer of the uterine corpus in the United States alone with $>10,000$ deaths (Siegel, Miller, \& Jemal, 2015). Most of these cases involve women over 40 years old, with a mean age of 61 years. There are slight variations in race, as African American women have a $6 \%$ lower rate of incidence, but $16 \%$ higher rate of death than Caucasian women. Most cases of endometrial cancer are of the Type I endometroid histologic type. If caught at an early stage prior to spread beyond the uterus, there is a favorable prognosis without need of adjuvant therapy.

It is becoming increasingly common to use robotic assistance in laparoscopic hysterectomies (Dharia \& Falcone, 2006). These procedures involve placing the patient in a steep Trendelenburg position, traditionally 24-30 degrees, so as to allow gravity to "lift" the abdominal organs away from the operative field. Some studies have shown that hemodynamic changes occur in patients positioned this way during an operation (Darlong, Kunhabdulla, \& Pandey, 2012). We propose that headaches, including migraines, can result from or be exacerbated in this manner. We have observed patients with a history of migraines experience breakthrough headaches postoperatively. Although the etiology of migraines remains unclear, neurochemical changes affecting cerebral blood flow have been implicated (Cutrer, 2006). In our study, we propose a link between Trendelenburg positioning and breakthrough headaches seen in patients with a history of migraines undergoing robotic assisted laparoscopic hysterectomies for endometrial carcinoma. 


\section{Methods}

On an IRB approved study, the next one hundred women undergoing robotic surgery for endometrial cancer after we initially had a patient diagnosed with a severe postoperative exacerbation of migraines were examined. The next 100 patients' charts were reviewed for the presence of the ICD-9 code of 346 (migraines). Discharge summaries were examined on all 100 patients to determine the presence of postoperative headaches and whether or not there was a pre-operative diagnosis of migraines. All patients received one dose of preoperative antibiotics according to hospital guidelines with the standard being cefoxitin or cefotetan if no allergies existed. No patients included in the study had spinal or epidural anesthesia. Standard positioning for the patients was 24 degrees of trendelenburg (maximum trendelenburg on the bed used for robotic surgery). No postoperative antibiotics were given. All patients received inpatient postoperative anticoagulation. Data were extracted and made unidentifiable including diagnoses, operative time, body mass index, estimated blood loss, transfusion rate and complications.

SPSS (IBM-SPSS Statistics, Armonk, New York, USA) was used for statistical analysis. All tests used were two-tailed. Independent samples $t$-test was used to compare appropriate variables. Fisher's exact was used to study categorical and normally distributed numerical data. Normality was tested for by the Shapiro-Wilk test. Mann-Whitney $\mathrm{U}$ test was used for skewed data. A $P$ value of 0.05 was considered significant.

\section{Results}

Records on 100 consecutive women undergoing robotic hysterectomy for endometrial cancer were examined. Table 1 demonstrates the demographic characteristics of the women in the study. Only women with grade 1 or 2 endometrioid adenocarcinomas were included to limit the chance of headaches being caused by a metastasis. Eleven women were found to have the diagnosis of migraine headaches with 89 women having no documented history of migraines or other headache syndromes. The mean age of women having a history of migraines was significantly lower than the mean age for those not having headaches $(\mathrm{p}<0.001)$. There was no significant difference in estimated blood loss (EBL), total skin to skin OR time or body mass index (BMI) (Table 1).

Table 1. Basic demographics and comparison of clinical information between patients with and without a history of migraines in columns 2-5. Columns 6-8 compare the demographics and clinical information between those with and without a headache exacerbation

\begin{tabular}{cccccccc}
\hline \multicolumn{7}{c}{ Demographics and comparison data } \\
\hline & $\begin{array}{c}\text { Whole } \\
\text { cohort } \\
(\mathrm{N}=100)\end{array}$ & $\begin{array}{c}\text { No migraine } \\
\text { history } \\
(89)\end{array}$ & $\begin{array}{c}\text { Migraine } \\
\text { history } \\
(11)\end{array}$ & p-value* & $\begin{array}{c}\text { Headache } \\
\text { exacerbation } \\
(6)\end{array}$ & $\begin{array}{c}\text { No headache } \\
\text { exacerbation } \\
(94)\end{array}$ & P-value* \\
\hline $\begin{array}{c}\text { Mean age } \\
\text { (years })\end{array}$ & 60 & 60 & 47 & $<0.001$ & 48 & 60 & 0.009 \\
$\begin{array}{c}\text { EBL } \\
(\mathrm{mL})\end{array}$ & 201 & 205 & 168 & 0.093 & 200 & 203 & 0.36 \\
$\begin{array}{c}\text { OR time } \\
(\text { minutes }) \\
\text { BMI } \\
\left(\mathrm{kg} / \mathrm{m}^{2}\right)\end{array}$ & 130 & 130 & 130 & 0.69 & 140 & 130 & 0.48 \\
\hline
\end{tabular}

*Mann-Whitney U Test.

Six women had exacerbations of headaches that were documented in their discharge summary (Table 1). Five of these women had a known history of migraines and one of these women had no known history of any headache syndrome. Women were significantly more likely to develop a post-operative headache if a history of migraines ( 5 of $11,45 \%$ versus 1 of $89,1.1 \%)(\mathrm{p}<0.001)$. Women with a post-operative severe headache $(6)$ were significantly younger than women that did not have post-operative headaches ( $48 \mathrm{vs.} 60, \mathrm{p}=0.009)$. There were no significant differences in EBL, OR time or BMI.

\section{Discussion}

Robots have dramatically affected modern surgery since their initial application to medicine less than forty years ago. It is important to avoid the use of robotic assistance when contraindications arise, such as a potential for induction of migraines in predisposed patients following operative Trendelenburg positioning. 
In our study, 11 out of 100 patients undergoing robotic assisted-laparoscopic surgery for endometrial carcinoma had a history positive for migraines. Five of eleven experienced a subjective migraine exacerbation. Of these five patients, two had prolonged postoperative hospital stays because of the migraine. This is not only uncomfortable for the patient, but increases overall health care costs and should be avoided if possible. Studies have shown that hemodynamic changes occur while the patient is in this position, including a significant decrease in stroke volume, cardiac output and mean arterial pressure, and increase in central venous pressure. These changes return to baseline following reversal of Trendelenburg positioning postoperatively, but they can still lead to hypoxia and hypercarbia during the procedure, to which the brain is especially sensitive. Decreased blood flow is detected by chemoreceptors and baroreceptors, which initiate a resulting compensatory intracerebral vasodilation to increase oxygen to the brain. This can subsequently increase intracranial pressure.

Since these physiologic occurrences have been implicated in the etiology of migraines, it is possible that these exacerbations were experienced as a result of the standard, steep Trendelenburg positioning throughout the operation. One study demonstrated that it would be adequate to conduct most gynecologic procedures at a reduced angle of Trendelenburg (28 degrees) (Gould C, Cull T, Wu Y, Osmundsen B, 2012). Even so, 24 degrees was the standard used on the patients in this series and six headaches still occurred. Procedures including colpopexies and hysterectomies for both benign and malignant cases often utilize these steep angles. Further studies are needed to determine exactly how Trendelenburg angling affects cerebral blood flow, and whether the hemodynamic changes experienced at a position of lesser angling would still result in postoperative breakthrough headaches in patients with history of migraines.

Several obvious confounding factors exist in this study. First of all, this study is limited by its retrospective nature. Both the pre-operative diagnosis of migraines or other headache syndromes, as well as the post-operative diagnosis of headache may have been under-reported. Second, this study was just a consecutive series of patients undergoing surgery for endometrial carcinoma. No attempt was made to randomize patients to different angles of Trendelenburg position. A study of patients with known headache syndromes randomized to different angles while measuring ocular pressures as a surrogate for intracranial pressures is needed to get a definitive answer.

Until further knowledge is developed on the subject, we at least recommend that patients with a history of migraines are warned that they may have an exacerbation of their migraines.

\section{Disclosure Statement}

None of the authors have any relevant conflicts of interest to report.

\section{References}

Benedet, J., Bender, H., Jones, H., Ngan, H., \& Pecorelli, S. (2000). FIGO Staging Classifications and Clinical Practice Guidelines in the Management of Gynecologic Cancers. Int J Gynecol Obstet, 70, 209-262. http://dx.doi.org/10.1016/S0020-7292(00)90001-8

Creutzberg, C., van Putten, W., \& Kope, P. (2000). Surgery and Postoperative Radiotherapy versus Surgery Alone for Patients with Stage-1 Endometrial Carcinoma: Multicentre Randomised Trial. Lancet, 355, 1404-1411. http://dx.doi.org/10.1016/S0140-6736(00)02139-5

Cutrer, M. (2006). Pathophysiologic Migraine. Semin Neurol, 26, 171-180. http://dx.doi.org/10.1055/s-2006-939917

Darlong, V., Kunhabdulla, N., \& Pandey, R. (2012). Hemodynamic Changes during Robotic Radical Prostatectomy. Saudi J Anaesth, 6, 213-218. http://dx.doi.org/10.4103/1658-354X.101210

Dharia, S., \& Falcone, T. (2005). Robotics in Reproductive Medicine. Fertil Steril, 84, 1-11. http://dx.doi.org/10.1016/j.fertnstert.2005.02.015

Gould, C., Cull, T., Wu, Y., \& Osmundsen, B. (2012). Blinded Measure of Trendelenburg Angle in Pelvic Robotic Surgery. J Min Inv Gynecol, 19, 465-468. http://dx.doi.org/10.1016/j.jmig.2012.03.014

Siegel, R. L., Miller, K. D., \& Jemal, A. (2015). Cancer Statistics, 2015. CA Cancer J Clin., 65, 5-29. http://dx.doi.org/10.3322/caac. 21254

\section{Copyrights}

Copyright for this article is retained by the author(s), with first publication rights granted to the journal.

This is an open-access article distributed under the terms and conditions of the Creative Commons Attribution license (http://creativecommons.org/licenses/by/3.0/). 